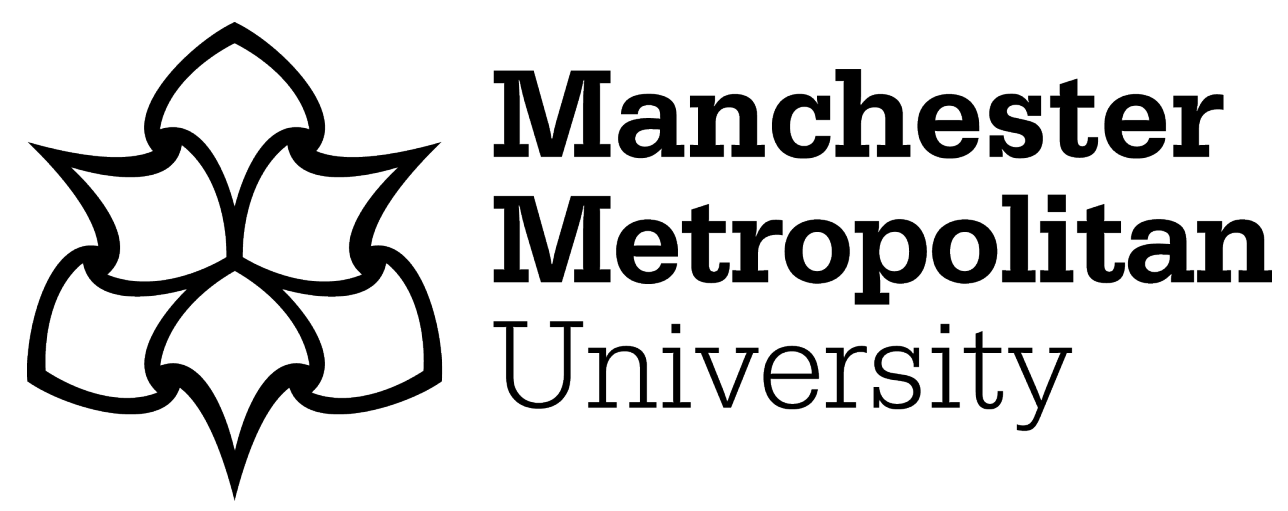

Whittington, Elsie ORCID logoORCID: https://orcid.org/0000-0003-24211251 (2019) Co-producing and Navigating Consent in Participatory Research with Young People. Journal of Children's Services, 14 (3). pp. 205-216. ISSN 1746-6660

Downloaded from: https://e-space.mmu.ac.uk/623450/

Version: Accepted Version

Publisher: Emerald

DOI: https://doi.org/10.1108/JCS-02-2019-0007

Please cite the published version 


\title{
Co-producing and Navigating Consent in Participa- tory Research with Young People
}

\author{
Elsie Whittington
}

Key words: consent, negotiation, Gillick, children's rights, participation, ethics

\section{Abstract:}

Research within the fields of youth sexuality and safeguarding, and ethical governance more broadly, has traditionally prioritised risk aversion over the rights of young people to participate in and shape research. This excludes younger people from setting agendas and directly communicating their lived experience to those in power.

This article describes and draws upon findings from an innovative two year participatory action research study exploring sexual consent with young people through embedded and participatory research across seven sites. The project was designed with young people and practised non-traditional approaches to research consent. As well as co-producing research data, the findings highlight how methods of co-enquiry and being explicit about the research consent process enabled young people to develop competence that can be applied in other contexts.

The paper addresses ethical tensions between young people's rights to participation and protection. It argues that alongside robust safeguarding procedures there is an equal need to develop robust participation and engagement strategies with an explicit focus on young people's competence, agency and rights to participate regardless of the perceived sensitivity of the topic.

The paper concludes with proposals for future youth centred research practice. These relate to research design, ethical governance processes around risk and sensitive topics, emphasis on working collaboratively with young people and practitioners, a greater focus on children and young people's rights - including Gillick competence and fluid models of consent. In doing so, it presents an essential point of reference for those seeking to co-produce research with young people in the UK and beyond. 


\section{Introduction}

For safeguarding, educational agendas and policy and practice to relate better to the people they seek to affect it is essential that research in these areas actively involve children and young people. There are a host of practical and ethical challenges that could arise from this. Many topics that are part of, or related to, safeguarding are considered sensitive and, in research terms, viewed as 'high-risk' especially if they are to be discussed with young people. While ethical considerations are undoubtedly important, age-specific power imbalances mean that younger researchers and children and young people are rarely able to set the agenda and directly communicate their lived experience to those in power (Allen, 2008; Cammarota and Fine, 2008; Tisdall, 2017). Their rights to participate in decisions that may affect them are routinely under prioritised and, in some instances, stifled by protective policies or practices, which seek to avoid, rather than manage risk (Tisdall, 2017).

The following paper's methodological focus reflects on some ethical tensions associated with modelling and celebrating youth agency in a participatory research context. The study committed to ensuring that the research questions and methods were shaped by young people, who chose to explore the topic of sexual consent.

Whilst exploring sexual consent participants in this study consistently implied sexual consent was: 'fluid', 'constantly renegotiated', 'communicated, verbally and non-verbally', 'voluntary', 'mutual' and 'withdrawable'. The terms they used to describe sexual consent unsurprisingly resonated with terms associated with Participatory Action Research (PAR) approaches and with youth work relationships that share a common concern with power sharing (Banks et al. 2011; Davies, 2009). Not only did this highlight the complexity of consent in sexual encounters but it called into question the parallel processes and practices of seeking and formalising consent to research participation. It became apparent that alternative processes of research consent needed to be explored. Thus, the author's experience of practicing non-traditional research consent is the primary focus of this paper. In doing so it presents an important point of reference for those seeking to proactively include young people in every phase of research.

This article begins by outlining key literature on sexual consent, children's rights, safeguarding, participatory research ethics and research consent. It then briefly describes the PAR project about sexual consent to contextualise the reflective commentary that follows. The author focuses in on the possibilities and tensions experienced while attempting to uphold participatory research principals and balance young people's

rights to protection and participation. It reflects on different processes of navigating consent with young people and advocates that a continuous reflexive approach to research consent that prioritises young people's rights to participation and education about sensitive topics is essential. The paper closes with a discussion about de-prioritising parental consent to research participation and the application of a Gillick approach to research.

The author acknowledges that anyone under 18 is legally afforded the status and protection of a 'child' (UNCRC 1989) However to avoid over use of 'children and young people' this paper refers to young people throughout to reflect how the participants defined themselves.

\section{Contextualising Consent: from sexual consent to research consent}


Issues of consent in varying contexts can be contentious and difficult to navigate. Debates and developments relating to sexual consent have emerged and shifted in focus over the last half century (See Whittington and Thomson, (2018) for a recent geneology of sexual consent in the UK). So too has the discourse around 'informed consent' to medical intervention and to research participation (Murray,1990; NelsonMarten and Rich, 1999; Wiles et al. 2005). Over this period attention to children and young people's rights and capacity to consent to sexual, medical and research encounters has come in and out of focus, usually in response to controversy and change.

A notable example (and significant to arguments later in this paper) is the 1982 Gillick vs West Norfolk case in the UK. This case was "the beginning not the conclusion" of developments, debates and negotiations around children's rights, parent's rights and the duty of doctors and the state in relation to medical treatment and sexual activity (De Cruz, 1987). The court recognised that young people under 16 are "capable of making a reasonable assessment of the advantages and disadvantages of the treatment proposed, so the consent, if given, can be properly and fairly described as true consent" (Gillick v West Norfolk, 1984). It resulted in the statement of an explicit methodology, known as the 'Gillick approach' for evaluating competence using Fraser guidelines ${ }^{1}$ (Thomson, 1995; De Cruz, 1987). This case encapsulated the tensions of the moment in relation to changing sexual practices, individualism, public health and children's rights. These tensions are still live today. For example in contemporary discussion about the content and 'age appropriateness' of new Relationship and Sex Education (RSE) in England's curriculum (EVAW, 2018); approaches to child protection (Pearce, 2013; Tisdall, 2017); and young people's rights to consent to research participation in their own right (Coyne, 2010; Pickles, 2019).

Presently public discourses surrounding young people's sexuality are acutely focused on risk, safety and exploitation (Clapton et al. 2012). This is not unjustified, given recent revelations of historic and institutional sexual violation. Consequently, there has been renewed policy and academic focus on defining who counts as children, how to recognise sexual agency and abuse in different contexts, and how best to balance children's rights to protection and participation (Firmin et al. 2016; Lefevre et al., 2018; Warrington and Beckett, 2015; Pearce, 2013). Much of the aforementioned work actively prioritises young people's experiences, opinions and rights while reframing discussion about protection. Yet there remains a gap in literature where "few UK researchers have explicitly explored sexual consent with young people" outside the context of violence and abuse (Coy et al. 2013:9; Whittington and Thomson, 2018, Whittington, 2019).

As sexual cultures shift and develop, there is a compelling case to include, and learn from young people in research (Coy et al. 2013). This will ensure education and safeguarding policy can respond to their needs, interests and experiences; not simply to adult fears, and extreme but minority experiences of trafficking and exploitation (Alldred and David, 2007; Whittington and Thomson, 2018; Carmody, 2009; Allen, 2008). In order to do this young people should be included in setting the agenda for new research that could inform RSE content and safeguarding policy and practice more broadly.

Researching 'sex' with young people however, is deemed 'high risk' by ethical review committees as stimulating conversations about sexual knowledge and practice can be risky or awkward and present a series of ethical dilemmas for researchers and practitioners (NCB, 2014). This in itself parallels and reinforces

\footnotetext{
1 'Gillick Competency' and 'Fraser guidelines' help practitioners to make judgements about a young person's capacity to 'make their own decisions and to understand the implications of those decisions' (NSPCC, 2018a), and thus their capacity to give 'informed consent' to, a medical procedure, treatment and sexual activity.
} 
anxieties about children's participation and access to information about sex that are visible in current discussions about the content of RSE (Robinson, 2012; EVAW, 2018).

Managing Risk in Research with Young People:

Lee \& Renzetti note that "we cannot safeguard people by avoiding sensitive or controversial research" (1990:252). A priority towards avoiding risk, and a limited view of child protection which overlooks the protective potential of engaging in research and reflective conversations can come at the expense of youth participation (Coyne, 2010; Tisdall, 2017; Cammarota and Fine, 2008). This limits young people's opportunities to be heard on matters of concern for them (Allen, 2008; Cammarota and Fine, 2008). Indeed ethical governance has been critiqued for a tendency to protect institutional power at the expense of community empowerment" (Malone et al. 2006:1915, cited in Banks et al. 2011:9).

By virtue of being a "political statement as well as a theory of knowledge" (Reason and Bradbury, 2011:10), participatory approaches can enable communities and researchers to approach research differently. A key aim of much participatory or collaborative knowledge production is that the topic and mode of enquiry are developed with participants who themselves become active in the research process. This provides an alternative to positivist research by focussing on the co-creation of experiences and findings rather than on generating generalisable data (Cammarota and Fine, 2008). Some of the benefits include: the democratisation of research process; rich findings that help to provide deeper understanding of social phenomena and a less extractive research process. Opportunities for learning and analysis are embedded in process and so retained by participants (Coghlan and Brydon Miller, 2014; Cammarota and Fine, 2008; Banks et al. 2011). The ways in which this is instigated and practiced vary according to the needs and interests of different participants, funders and researchers.

The research, child protection and educational contexts above combine to create a difficult landscape to navigate if attempting to co-produce research with children and young people about sexual consent, or other sensitive topics.

Weston (2010) has suggested that the role of ethics is not to moralise or provide rules but to:

[...] ]offer some tools for thinking about difficult matters[...] recognizing that the world is seldom so simple or clear cut. Struggle and uncertainty are part of ethics, as they are part of life. (2010:8)

As such it is important to weigh up the relative risk and ethical considerations of involving young people in research against young people's rights to freedom, participation, and inclusion in matters that concern them. This involves viewing ethics as a reflexive and ongoing process (Beckett and Warrington, 2015) which includes ethical governance considerations as well as safeguarding and risk management.

In order to cultivate a more ethical sexual culture and embolden young people with protective knowledge it is essential that we create space for talking about risks and consent in an open and exploratory way (NCB, 2014; Carmody, 2009; Warrington, 2018). For the project below it was deemed ethically and politically important that young people contribute to new agendas for RSE and safeguarding now and in the future. PAR which focuses on education can attend to both immediate and longer-term risks for both the individual and for society more widely by managing rather than avoiding risk (Banks et al. 2011; Weston, 2010). Thus, the research outlined below had a key aim of 'starting where young people are at' (Davies, 2009) to collaboratively develop a research project about sexual health, wellbeing and education. 


\section{The Participatory Research Project: Methodology}

This research project was designed with young people and aimed to co-produce an account of sexual consent that is congruent with young peoples' lived experiences. The research was co-funded by the UK's largest sexual health and wellbeing charity for young people (the charity hereafter) and they supported the commitment to PAR principals. As such, the research aims, questions and methodology were co-created throughout the research process with the young people who were involved. In order to enable varied youth participation the researcher was hosted to run and support a series of action based projects in seven sites in England outlined below.

In PAR research and practice, design, process, analysis and findings are often interwoven and it can be difficult to explain a project in discrete sections, however for brevity the project can be described in three phases.

1. Research development and piloting (Oct 2014 - Nov 2015): The charity's participation groups, an alternative youth group and a university.

2. Youth Action projects (Oct 2015-June 2016): A multicultural all-girls secondary school and an inner city youth club in an area affected by gang activity and other challenging issues.

3. Practitioner insight (Feb 2016-July 2016): Revisiting an Education hub of the charity and a sanctuary and supported living home for young people recently migrated to the UK. This phase involved research with educational practitioners who were all tasked with delivering 'consent education'. Practitioner participation is not the focus of this paper so phase three will not be discussed here.

Members of staff at each site became gatekeepers and allies supporting recruitment by mediating the researcher's access to groups and advocating for the research intervention. The study generated data about sexual consent and sex education with 103 young people aged 13-25 and 12 educational practitioners. 71 young women, 31 young men and one young person who identified as non-binary participated. Seventyfive participants were under 18.

The topic of study, the age and potential vulnerability of the participants, and the public and group work nature of the project were significant factors that meant this research was considered 'high risk' by ethical governance criteria. These concerns were attended to in detail in the ethical review application which was granted approval. Much of the application highlighted the researcher's experience as a practitioner and their knowledge and competence regarding safeguarding practice and ethically managing risky conversations. It also drew on the support of the co-funder charity which had robust safeguarding policies and procedures for disclosures.

In line with participatory approaches, ethics was framed and practiced as an ongoing process of "reflexive concern, rather than a discrete procedural requirement" (Beckett and Warrington, 2015:11) in all phases of the research. This included phase one which began before formal ethical approval was gained, but ethics were also revisited at every stage as all participants were given the space to consent, or withdraw. Additionally some amendments were made to the ethics application during the research process. 
The ways in which data was captured throughout the work were negotiated with participants according to their interest in the research and data collection elements of the project. In the early stages of research encounters activities were captured with reflective field notes or by photographing group outputs (such as spider diagrams and definitions) to maintain anonymity before consent was more formally negotiated. As relationships with participants developed and a clearer sense of their interests and consent to the process emerged, data that would allow individual comments and views to be attributed was co-produced and recorded.

\section{Co-producing the Research:}

Generally, it would be expected that a detailed methodology, timetable and ethical application has been submitted and verified before access to institutions and young people is granted (Heath et al. 2009:64). There are valuable and important reasons behind these requirements which can ensure that research endeavours do not under inform or exploit potential participants (Wiles et al. 2005). However they leave little room for participants to contribute meaningfully to the design of research, with several authors noting that traditional ethical review processes and funding applications do not easily accommodate a more contextual, community focussed and reflexive approach to ethics (Weston, 2010; Banks et al. 2011; Coghlan and Brydon Miller, 2014).

Phase one, which occurred before ethical approval was sought, can be characterised in Sassen's terms 'before the method' (2013). It is the creative, messy thinking and networking that is often not spoken about in papers and ethical applications but which is essential for gaining insight into what methods might actually be practical, and which questions are realistic in conducting a collaborative study. During this phase a group of young volunteers, all $16+$, at the charity were consulted about the research topic. Then a series of exploratory workshops were delivered to co-develop research methods and ways of engaging with other groups of young people who may not ordinarily get involved in this kind of work. Interactive research activities were co-designed to enable and elicit group learning and conversation about the nuances of the chosen topic - sexual consent ${ }^{2}$.

In phase two the researcher spent over a school term at each site where research activities involved interactive workshops, discussion groups, film projects and the co-development of educational tools and resources. She also practiced ethnographic methods such as participant observation and taking field notes. At the school the researcher was invited to support a year eleven class who were doing a project on sexual consent. Here she performed a class assistant role at times, and supported different groups with tasks such as blog writing, film making and school conference planning in addition to facilitating small group discussion sessions that could be transcribed. At the youth club the researcher had been invited to facilitate a film project (part of the research/action designed by the group in phase one). Rather than start with the film project the researcher spent time at the club developing relationships, running drop in discussion sessions and cultivating interest in the chance to engage in participatory research and a film project about sexual consent. The prolonged period at each site helped develop rapport with potential participants and

\footnotetext{
2 Many of these activities have been developed into training and educational resources for educators. These are freely available at https://learn.brook.org.uk
} 
meant that young people at the youth club and school who might not ordinarily self-select into this kind of research felt confident about navigating their participation and subsequent consent to participation.

The methods and cyclical, reflective nature of this research have produced a learning situation for the participants and the research generating "learning about learning, or meta learning", both in situ and during analysis (Coghaln and Brdon-Miller, 2014:240). Sessions involved much co-analysis through discursive activities, however the final thematic analysis of the research data about 'what young people think about consent' was analysed by the researcher (a limitation of this as a truly participatory project). These findings are discussed elsewhere and outside the scope of this paper (See Whittington and Thomson, 2018, Whittington, 2019 and forthcoming work). The methodological learning and process that can contribute further to youth participatory research agendas are discussed below.

\section{Method as Pedagogy:}

In their publication about teaching sexual consent The National Children's Bureau note that "asking ourselves and young people what we think consent means is revealing" (NCB, 2014:2). This was certainly the case in the research outlined above. Not only did research conversations with young people highlight some limitations of current formal education around sexual consent (see Whittington and Thomson, 2018; Whittington, 2019), they also sparked critical conversations about consent in every-day interactions and in the research relationship itself.

Group research activities enabled the researcher to capture the opinions and learning experiences of participants, many of whom were initially un-interested in or had not heard about the term 'sexual consent' before this project. A positive impact of this research approach is discussed below. It reflects a wider finding from the data analysis of increased critical thinking as a result of participation in the project.

At the Youth Club Shanella ${ }^{3}$, like other attendees had not covered sexual consent in school. Research intervention here meant that over time she went from having "never heard about consent before you [researcher] came to the club" and initially speaking about it in quite an abstracted way, to recognising the complexities and nuances involved in sexual negotiation.

Elsie: Why is body language risky?

Shanella: Because it can be misinterpreted. So it's like, someone, like, their body could be saying one thing, but then they're not actually saying that, kind of thing, and especially like, downstairs I was talking to Dave, and umm, he was saying 'what if someone's afraid of the other person, but they don't wanna say it'. So, you know, you don't really know if what their body's telling you is the truth.

Shanella's interaction with the topic, researcher, and youth workers illustrates how participation can enable critical thinking and reflection, which in turn contribute to building awareness and the capacity for selfprotection (Robinson, 2012; Carmody, 2009). Throughout the project Shanella, and many other participants developed a new vocabulary, began to construct consent in a more nuanced way and were able to reflect on and develop terms that had salience for them and their peers.

\footnotetext{
${ }^{3}$ Young participants have chosen pseudonyms.
} 
By practicing a method of co-enquiry which viewed participants as experts and creators of knowledge the research encounters became spaces in which the young people developed skills and gained information as well as co-producing research data (Chambers, 2004, Cammarota and Fine, 2008). This was acknowledged by the participants themselves, an example of which is 15 -year-old Nina, speaking about being involved in the research in her school:

“I just realised that like we don't really talk about this. Like I think without this [sessions with the researcher] I wouldn't talk about consent [...] and it's good to know this stuff"

The quote above demonstrates that 'risky', awkward and critical research conversations can be managed safely and become a resource for learning and developing competence which is a key part of safeguarding. This paper now moves onto discuss how research consent can be negotiated in youth centred and nontraditional ways.

\section{Co-producing Youth Centred Research Consent:}

By encouraging participants to think critically about consent in a sexual context they were empowered to question and reflect on their rights to consent in other circumstances - most explicitly- the research process. It was acknowledged that the process of obtaining formal 'one off' written consent to research (required by university research governance) jarred, challenging the culture of a project that was itself fluid and iterative. Thus, by paying close attention to how young people understood and framed sexual consent the researcher, with support of practitioners at different sites, made a special effort to navigate research consent in a way that mirrored participants view that consent is about "asking every time".

\section{Navigating Research Consent:}

Within all forms of social science research 'informed consent' is considered a key element to ethical research participation (David et al. 2010). Yet current usage of 'informed consent' (in research) has also come under criticism for being too static when in practice it can be a complex and changeable element of the research process (Boddy and Oliver, 2010; David et al. 2010; Alderson and Morrow, 2011). Given the participatory, and therefore semi-planned nature of the action projects in this study, it was not always possible to provide enough information to participants for them to " $k$ now' and 'understand' what they were 'getting themselves into'" (David et al. 2010:348) from the beginning. For instance, while research activities were loosely planned in advance of some sessions the participants were encouraged and supported to ask questions of each other and the researcher and to lead and direct discussions. This disrupted traditional research dynamics.

Ensuring the research participation and consent were informed and voluntary was attempted in a variety of ways at each site. Sometimes formal written consent was sought at the start of a project or session; other times it was not gained until later in research encounters. Both approaches had their challenges and rewards. In order to ensure participation was ethical the author constantly checked in with participants 
about their expectations and understandings of the research. Participants were regularly reminded that they could leave, or, at least, disengage at any time. An example of practicing continuous and more explicit processes of research consent is discussed below.

\section{'Asking Every Time'}

During research activities in the first week at the school site, where consent forms were signed at the start of the research partnership, participants often spoke about how sexual consent had to be sought "every time". In line with this the researcher decided to model this approach with research consent and brought fresh consent forms each week.

Elsie: [...] you know that you did the definitions of consent last week, and some people thought that like consent is mutual; and lots of people said it's like retractable and that it has to be asked for every time.

Adz + Nina: Yea

Elsie: Well cos of that I thought that I should ask every time [They all laughed at this] to make sure that I am doing it properly. So, I brought in some extra ones this week for you all to do again if you're willing [...]

Field notes and transcripts from subsequent weeks noted that as time went on the participants did not feel they needed to sign new forms and that they were "getting in the way" (Azmin) of conversations and activities. Interestingly this perspective seemed to mirror a view shared by some research participants that in sexual context explicitly talking about 'consent' can disrupt the flow of interaction and "ruin the moment" (Charlie).

The researcher persisted each week in requesting signed consent despite it feeling a little awkward. Through persisting in this way the consent form became a useful prop for exposing the research process. By continually negotiating research consent it exposed power relations that are rarely made explicit and stimulated conversations and learning about power, decision-making, and agency in different spaces. This self-conscious activity - although part of an approach to addressing research ethics in the PAR context also helpfully mirrored realities of formalising or negotiating consent to sexual activity, highlighting the temporal/context specific nature of consent and the need for constant re-negotiation. In modelling an explicit process of research consent these interactions could be considered an opportunity to develop skills for negotiating consent that could be applied in different scenarios.

Establishing and recording formal consent every time, while enabling research participation to be fluid was time consuming. Significant sections of group discussion centred around the form limiting time to discuss other things. It also made the research process and opportunities to 'capture' data precarious as participation waxed and waned over the course of the projects. For instance, at the youth club there were weeks where there was little interest in talking about consent or engaging with the researcher. Similarly, at the school there were occasions where no students wanted to participate in smaller group sessions that involved leaving the classroom. While this was sometimes frustrating for the researcher, it suggested that she was practising 'good consent' in that, (potential) participants felt able to say 'no', dissent or negotiate different levels of participation in the research process. This indicated that, when they did volunteer, their contributions were genuine and freely given. 


\section{Prioritising Young People's Right to Participation}

It is not unheard of for researchers to "rely on children's consent without parents' consent" (Alderson, 2005, Morris et al. 2012; Pickles, 2019) however this is largely un-reported and not often included in ethical review applications, regardless of the perceived risk of topic or age of participants (Coyne, 2010). The educational nature of this research project and the more continuous process of consent practised with young participants called the standard of parent/carer consent to participation into question at each research site. The researcher experienced significant tension here between reconciling rights to participation and protection. On the one hand upholding young people's rights to: information/education, confidentiality and a recognition of developing capacity (UNCRC, 1989): on the other, adhering to common practices of safeguarding which view parents/carers as protective gatekeepers (NSPCC, 2018b; Alderson and Morrow; 2011).

A number of scholars note that "viewing children as social actors adds new complexities and uncertainties to the research process, creates greater scope for ethical dilemmas and imposes new responsibilities on researchers, particularly in relation to the consent process" (Coyne, 2010:227; Christensen and Prout, 2002). Additionally arguments and case law relating to the Gillick ruling and the UNCRC offer grounds for viewing young people (in line with their evolving capacity) as capable of consenting and negotiating decision making about research participation (Coyne, 2010).

Although Gillick competency and Fraser guidelines arose from a medical context, the approach is used more widely by practitioners working with young people under 16 to establish whether they are competent enough to make their own decisions and to give 'informed consent' (NSPCC, 2018a). In dialogue with staff at each venue and given the topic of study, a Gillick approach to research consent was practiced at all sites, apart from the school based site where the teacher acted in loco-parentis. Combining this with a PAR and youth work approach it was seen as essential to support young people to make their own choices about participating in the research. Thus, the researcher and particularly practitioners who knew (potential) participants well not only assessed competence but also actively informed and negotiated levels of participation with young people in terms that made sense to them.

Making parental consent for young people under 16 a requirement for any level of participation in the educational research activities was deemed, by the practitioners hosting the research, as exclusive and out of step with sexual health and educational service provision. This echoes arguments by Pickles who notes that:

“Excluding under 16's from sensitive research when practitioner services identify that there is a specific social need for this widens the fissures between academic research and practitioner based operations. This creates an inconsistent ethical framework that excludes young people from partaking in research, due to the adult-centric perceptions that curtail agency rather than provide the safest means to empower" (2019:12)

Putting the approach above into practice was anxiety inducing and caused some tension for the researcher. Following the practices of the venues did not always align with the ethical governance guidance at the university. This highlights a missmatch in what is often viewed as best practice regarding safeguarding, 
knowledge production and dissemination of data. Embracing and responding to these and other dilemmas ${ }^{4}$ reflexively and collectively with practitioners and young participants arguably resulted in a youth centred and ethical practice, something that can be limited when gaining parental consent, and children's consent/assent at the start of a research project (Coyne, 2010; Skelton, 2008; Pickles, 2019).

Despite some recognised shortcomings (See Pearce, 2013; Cave, 2014 for critiques of Gillick approach), foregoing parental consent is more often accepted in what could be seen as 'higher risk' areas (Pickles, 2019). It may be seen as more 'defensible' to deprioritise parental consent in situations where the research concerns confidential areas (such as mental health, sexual and reproductive health provision or LGBT+ services). This is explored in detail by Pickles who argues "the standard of parental consent for [young LGBT+] participants [could] potentially put them in greater harm" (2019:7). Paradoxically parental consent is still generally assumed to be required as the norm in settings where there is less potential risk of harm.

Where parental consent is still routinely prioritised, regardless of the topic under research, it can maintain a problematic ethic, which is inconsistent with children's rights and safeguarding agendas (Coyne, 2010; Pickles, 2019). There is a parallel here with legislation in England that will afford parents the right to withdraw their children from school RSE classes which arguably serve an important role in safeguarding through equipping students with knowledge that could help them navigate a changing social/sexual world (EVAW, 2018; Robinson, 2012; Whittington and Thomson, 2018).

Coyne notes that "The parental consent requirement may be seen as a well-intentioned safeguard meant to protect children" (2010:228) but highlights that this can restrict their ability to participate voluntarily in research. She goes further, suggesting that parental consent can at times result in researcher complacency regarding time and energy spent informing and negotiation participation with the young participants (2010). There are a number of issues to contend with if parental consent is not sought and this approach is not without its tensions/risks. Ultimately, it requires gatekeeping organisations and researchers to be confident in assessing and managing risk, and to recognise that the benefits of youth participation mitigate the risk of deprioritising parent/carer input. The decision to forego parental consent in this study certainly ensured more time and consideration was given to ethically negotiating consent and participation throughout the research. This resulted in positive learning outcomes for young people as well as data for analysis. By continuing to negotiate participation and to acknowledge power dynamics the researcher ensured that young peoples' right to consent - or not - to each session, was actively upheld. This arguably created more safety for all concerned.

\section{Conclusion: towards a youth centred ethic of participation.}

In the interests of promoting, a more youth centred approach to research ethics and consent this paper has showcased work which used PAR and prioritised young people's rights, desires and competence to be heard on matters of concern for them (Pickles, 2019; Morris et al. 2012). Research with young people around 'risky' topics present a number of challenges. However, this article demonstrated that avoiding sensitive research topics, such as sexual consent, can reduce opportunities to co-produce knowledge with

\footnotetext{
${ }^{4}$ The youth led film project at one site for instance required a different approach given potential issues of anonymity, photo/film release and research consent which is not the focus of the current paper.
} 
young people that can actively contribute to safeguarding in different contexts (Lee and Renzetti, 1990; Robinson, 2012).

The paper has demonstrated how utilising non-traditional models of research design and consent can enable a more ethical and democratic research process. This research was rooted in a commitment to active and reflexive ethics (Warrington and Beckett, 2015) and a youth work and participatory politics that sought to acknowledge power relations and prioritise young people's autonomy and participation as much as possible.

The paper advocated that facilitating and supporting younger people to make informed choices about participation in research provides learning that can be a protective factor as they navigate decision making in other areas of their lives. Here learning is characterised by gaining vocabulary, skills and concepts that help make sense of experiences critically and contribute to safeguarding by developing competence.

It is argued that, alongside robust safeguarding procedures that seek to manage rather than avoid risk, youth focused research should have participation and engagement strategies with an explicit focus on acknowledging and nurturing young people's competence, agency and rights to participate regardless of the perceived sensitivity of the topic (UNCRC, 1989; Coyne, 2010).

By working in partnership with practitioners and young people the researcher ensured participants were informed about the research process in terms that made sense to them. They applied what could be termed a Gillick approach to the research by prioritising young people's confidentiality and autonomy to make decisions about participation above a need to establish parental consent/permission. This paper argues that a youth centred ethic for research would routinely prioritise young people's rights to give informed consent and that ethical review applications should explicitly address how this is to be obtained and supported. This would also have the effect of widening access as young people, deemed competent, who wished to participate in research could not be excluded for lack of parent/carer consent.

Learning from this research therefore suggests the following practice proposals for future youth centred research practice:

- Introduction of an exploratory 'before the method' stage of research (Sassen, 2013) as standard would enhance young people's opportunities to contribute to research and agendas and challenge adult-centric policies.

- Current ethical review guidelines would benefit from revision to support managed risks and flexibility with the balance between participation and protection reviewed (Coyne, 2010).

- Emphasis on working collaboratively with young people and practitioners and a greater focus on children and young people's rights - including Gillick competence and fluid models of consent are required. Researchers need to consider competence and risk in a way that is congruent with both research ethics and ethics of intergenerational inclusion (Banks et al. 2011; Cammarota and Fine, 2008; Pickles, 2019).

It has been shown that maintaining a focus on the ongoing process of research consent can scaffold ethical research in 'sensitive' areas. Modelling respect for young people's capacity to make informed choices keeps them safe in the research process whilst emboldening them to explore risky topics and develop both their confidence and competence to navigate decision making in differing contexts. 


\section{Acknowledgements}

I would like to thank all the participants who collaborated in this research and the input, support and advice of practitioners at each site. Thanks also to my reviewers and the editors for their generous and constructive feedback and to Jenny Lloyd.

The research was co-funded by Brook and The Centre for Innovation and Research in Childhood and Youth at the University of Sussex. Both organisations were incredibly supportive in enabling a youth centred and participatory approach.

\section{References:}

1. Alderson, P. and Morrow, V. (2011) The ethics of research with children and young people: a practical handbook. SAGE Publications Ltd. London

2. Alldred, P. and David, M. E. (2007) Get real about sex: The politics and practice of sex education. Open University Press, Maidenhead.

3. Allen, L. (2008) Young people's 'agency' in sexuality research using visual methods. Journal of Youth Studies 11(6): 565-577

4. Banks. S, Craig. G, Pain, R. Summebell, C. (2011) Community-based Participatory Research: Ethical Challenges, Durham Community Research Team, Centre for Social Justice and Community Action, Durham University

5. Beckett, H. and Warrington, C. (2015) 'Making justice work : experiences of criminal justice for children and young people affected by sexual exploitation as victims and witnesses'. University of Bedfordshire.

6. Boddy. J, and Oliver. C, (2010). Research governance in children's services: the scope for new advice, Research Report DFE-RR072, Department for Education, HM Government.

7. Cammarota, J. and Fine, M. (2008) 'Youth Participatory Action Research: A Pedagogy of Transformational Resistance', in Cammarota, J. and Fine, M (Eds) Revolutionizing Education: Youth Participatory Action Research in Motion, Routledge, London, pp. 1-12

8. Carmody, M. (2009). The sex and ethics violence prevention program. Melbourne: Palgrave Macmillan.

9. Cave, E. (2014) 'Goodbye Gillick? Identifying and Resolving Problems with the Concept of Child Competence', Legal Studies, 34(1):103

10. Christensen P and Prout A. (2002). Working with ethical symmetry in social research with children. Childhood, 9:477-497

11. Clapton, G., Cree, V. and Smith, M. (2012), Moral panics, claims-making and child protection in the UK, British Journal of Social Work, Vol. 43(4):803-812.

12. Brydon-Miller, M. and Coghlan, D. (2014) 'The big picture: Implications and imperatives for the ac-tion research community from the SAGE Encyclopedia of Action Research', Action Research, 12(2), pp. 224-233

13. Coy, M, Kelly, L, Elvines, F. Garner, M. and Kanyeredzi, A. (2013), "Sex without consent, I suppose that is rape": How young people in England understand sexual consent. Children's Commissioner's Inquiry into Child Sexual Exploitation in Gangs and Groups. Office of the Children's commissioner

14. Coyne, I. (2010). Research with Children and Young People: The Issue of Parental (Proxy) Consent. Children \& Society.

15. David. M, Edwards. R, and Alldred. P, (2010), Children and School-based Research: 'informred consent' or 'educated consent'?, British Education Journal, Vol. 27(3):347-365

16. Davies. B, (2009), In Defence of Youth Work, 'The open letter', https://indefenceofyouthwork.com/the-indefence-of-youth-work-letter-2/

17. De Cruz, S. P. (1987), Parents, Doctors and Children: The Gillick Case and Beyond, Journal of Social Welfare and Family Law, Vol. 9(2), pp. 93-108. 
18. End Violence against Women (EVAW) coalition, (2018), Relationships \& Sex Education and schools' duties to protect girls from sexual harassment and assault ' open letter to Secretary of State Department for Education, available from: https://www.endviolenceagainstwomen.org.uk/wp-content/uploads/EVAW-Coalition-to-Damian-Hinds-7-Nov-18.pdf

19. Firmin, C. Warrington, C and Pearce, J (2016).Sexual exploitation and its impact on developing sexualities and sexual relationships: the need for contextual social work intervention, British Journal of Social Work, 46 (8), pp.2318-2337.

20. Gillick V West Norfolk, (1984), United Kingdom House of Lords Decisions, Gillick v West Norfolk \& Wisbech Area Health Authority [1985] UKHL 7 (17 October 1985)

21. Heath, S. Brooks, R. Cleaver, E. Ireland, E. (2009) Researching young people's lives, Sage publications, Available from http://dx.doi.org/10.4135/9781446249420.n4

22. Lee, R. and Renzetti, C. (1990), 'The Problems of researching sensitive topics: An overview and introduction', American Behavioral Scientist, 33(5), 510-528.

23. Lefevre, M., Hickle, K. and Luckock, B. (2018), “Both/And' Not 'Either/Or': Reconciling Rights to Protection and Participation in Working with Child Sexual Exploitation', The British Journal of Social Work, 0:1-19

24. Morris, A., Hegarty, K., and Humphreys, C. (2012) Ethical and safe: research with children about domestic violence. Research Ethics 8(2): 125-139.

25. Murray P. M. (1990). The History of Informed Consent. The lowa Orthopaedic Journal, 10, 104-109.

26. National Children's Bureau (NCB), (2014) The Sex educational supplement: the consent issue, published by the Sex Education forum and National Children's Bureau, Issue 2, London

27. Nelson-Marten P, Rich BA (1999). A historical perspective of informed consent in clinical practice and research. Seminars in Oncology Nursing; 15:81-8.

28. NSPCC (2018) A child's legal rights: Gillick competency and Fraser guidelines. Available from: https://www.nspcc.org.uk/preventing-abuse/child-protection-system/legal-definition-child-rights-law/gillick-competency-fraser-guidelines/\#pageref11215

29. NSPCC (2018), Research with children: ethics, safety and avoiding harm, available from: https://learning.nspcc.org.uk/research-resources/briefings/research-with-children-ethics-safety-avoiding-harm/

30. Pearce J. (2013), A Social Model of 'Abused Consent'. In: Melrose M., Pearce J. (Eds.) Critical Perspectives on Child Sexual Exploitation and Related Trafficking. Palgrave Macmillan, London

31. Pickles, J. (2019) 'Including and involving young people (under 18's) in hate research without the consent of parents', Qualitative Research. doi: 10.1177/1468794118816622.

32. Reason, P. and Bradbury, H , (2011). Introduction: Inquiry and Participation in Search of a World Worthy of Human Aspiration, in Reason, P. and Bradbury, H. (Eds), Handbook of action research. London: SAGE, pp. 114

33. Robinson, K. (2012), 'Difficult citizenship' : the precarious relationships between childhood, sexuality and access to knowledge, Sexualities, Vol. 15 (3-4):257-276

34. Sassen. S, (2013), "Before Method: Analytic Tactics to Decipher the Global-An Argument and Its Responses, Part I", The Pluralist, Vol. 8(3), pp. 79-82

35. Skelton, T. (2008) 'Research with children and young people: exploring the tensions between ethics, competence and participation', Children's geographies, Vol. 6(1):21-36

36. Tisdall, E.K. (2017) Conceptualising children and young people's participation: examining vulnerability, social accountability and co-production, The International Journal of Human Rights, 21:1, 59-75

37. United Nations Convention on the Rights of the Child (UNCRC) (1989), United Nations Convention on the Rights of the Child, Availbe from: https://downloads.unicef.org.uk/wp- content/uploads/2010/05/UNCRC united nations convention on the rights of the child.pdf

38. Weston, A. (2010). A practical companion to ethics. 4th ed. Oxford University Press, New York 
39. Whittington. E, and Thomson. R, (2018) Education for consent: beyond the binary. In Sanjakdar, F. and Yip, A. (Eds) Critical Pedagogy, Sexuality Education and Young People: Issues about Democracy and Active Citizenry. Peter Lang, New York, pp. 49-64

40. Whittington, Elsie (2019) Understanding sexual consent: a participatory approach with young people. Doctoral thesis (PhD), University of Sussex.

41. Wiles, R., Heath, S., Crow, G., \& Charles, V. (2005) Informed Consent in Social Research: A Literature Review, ESRC National Centre for Research Methods, NCRM Methods Review Papers NCRM/001 Available from: http://eprints.ncrm.ac.uk/85/1/MethodsReviewPaperNCRM-001.pdf

42. Warrington, C. (2018), Children and Young People's participation in research to address sexual violence; Ethical working paper, Institute of Applied Social Research. Version:16/11/18 